solidate facilities, and thus to save money.

Seismologists in universities will be anxious to see that data from seismological observatories will still be readily available under any new arrangements. This is what has tentatively been decided: the National Earthquake Information Center, which issues data on the preliminary location of epicentres of seismic events around the world, will be transferred to USGS, but more complete data will continue to be available from NOAA's Environmental Data Service. In other words, seismology data will be available from the same sources, but half will be managed by USGS and the rest by NOAA. Small wonder that one NOAA official described the whole situation this week as "a mess".

As for Project Stormfury, it is being "suspended" because NOAA does not have enough suitably equipped planes. NOAA was planning to move the project from the Atlantic, where it has had dubious success in mitigating the effects of hurricanes by seeding, to the Pacific. The activities of the National Hurricane Research Center will also be scaled down.

The consolidation of earthquake research within USGS is a casualty of President Nixon's cutback on federal expenditure this year, but it must also be acknowledged that there have been many complaints during the past few years that earthquake research is poorly coordinated in the federal government -the latest such complaint came from the General Accounting Office last year. Those who have argued for coordination will be the first to complain, however, if their recommendations are used as excuses for cutbacks.

\section{INTERSTELLAR COMMUNICATION Eye on the Future}

by our Cosmology Correspondent "WE now have the technological capability of mounting an effective search for extraterrestrial intelligent life." This is the principal conclusion reached by B. M. Oliver after the Project Cyclops summer study programme, funded by NASA, of which he was codirector. The full report of that summer study has now been published, and provides perhaps the most detailed study of the interstellar communication problem now available (copies may be obtained from John Billingham, NASA/ Ames Research Center, Code LT, Moffett Field, California 94035).

One-third of this 240-page report deals with the fundamental problem of life in the universe, sets out reasons for attempting communication and determines the most effective means of contact. Not surprisingly, it turns out that electromagnetic radiation is the best tool for the job; the rest of the report, which specifies in considerable detail the antenna system needed, is where this study has the edge over previous work.

The size of instrument which the Cyclops team require is some 3 to $5 \mathrm{~km}$ diameter. They suggest that a circular complex of antennae, each 100 metres in diameter, surrounding a control room complex would be suitable for the job, the antennae being linked and phase switched to mimic one giant steerable array. This huge phased microwave antenna would be useful for many purposes; some idea of its power is given by the analogy that it could map Venus by radar as accurately as the Moon is mapped today, or Pluto with the accuracy now available for Mars studies. The advantages to radio astronomy are an obvious fringe benefit. An order of magnitude more powerful than existing arrays, the Cyclops system could also incorporate optical telescopes for simultaneous observation of sources. The sensitivity of Cyclops would be $4 \times 10^{6}$ times that of the late Ozma system (for a detailed comparison of Cyclops and Ozma see table) and could detect signals from thousands of light years away, assuming a plausible power output from the source.

Table 1 Comparison of Ozma and Cyclops Parameters

\begin{tabular}{lcc}
\hline \multicolumn{1}{c}{ Parameter } & Ozma & Cyclops \\
Antenna diameter & $26 \mathrm{~m}$ & $3,160 \mathrm{~m}$ \\
Antenna efficiency & 0.5 & 0.8 \\
$\begin{array}{l}\text { System noise temper- } \\
\quad \text { ature }\end{array}$ & $350 \mathrm{~K}$ & $20 \mathrm{~K}$ \\
$\begin{array}{l}\text { Resolved bandwidth } \\
\text { Integrating time }\end{array}$ & $100 \mathrm{~Hz}$ & $0.1 \mathrm{~Hz}$ \\
$\begin{array}{l}\text { Instantaneous band- } \\
\text { width }\end{array}$ & $100 \mathrm{~s}$ & $10 \mathrm{~s}$ \\
& $100 \mathrm{~Hz}$ & $200 \mathrm{MHz}$ \\
\hline
\end{tabular}

What would all this cost? According to the Cyclops study group, $\$ 600$ million per annum would allow preliminary planning and site development over 3 years followed by antenna construction at a rate of 100 per year. This compares not unfavourably with large projects such as Concorde, and although vastly greater than any previous scientific budget, is not entirely out of court.

Would the benefits be worth the cost? Certainly, such sums have been spent in the past, and are being spent today, on projects of little or no value to mankind. Even if the assumptions made in the study are completely correct, contact with a superior civilization would be unlikely for decades at least. J. C. G. Walker, writing in this issue of Nature (p. 379), is rather less optimistic. Although he agrees that such communication is technologically feasible, he believes that a successful search for extraterrestrial civilizations might require more than a thousand years, even if most habitable planets are occupied by communicative civilizations.

Whether or not such contact is desirable remains largely a philosophical question, and the devotion of some detailed consideration to the use of Cyclops as a research tool could be regarded as an attempt by the team to justify its otherwise abstract project.

Certainly radio astronomy could benefit greatly by being given the funds for an order of magnitude improvement in observation instead of building more instruments comparable with those now in commission. The scale of expenditure suggested for Cyclops, however, runs at four times the total annual expenditure of the British Science $\mathrm{Re}$ search Council. Perhaps the question is whether it is more efficient or more satisfying to spend $\$ 600$ million a year asking the stars for, say, a cure for cancer or to spend the same sum on cancer research on Earth.

\section{Short Notes}

\section{RIP}

AN item on page 1 of the January 31 issue of the New York Times invited readers to turn to page 38 for an article about how President Nixon is revamping "the entire top echelon of the federal science establishment". Page 38 was, appropriately, the obituaries page. (The article appeared on page 42.)

\section{Kennedy Bill}

SOME members of the Administration believe that the recent reorganization of the White House Policy machinery may have pulled the rug from under Senator Kennedy's National Science Policy and Priorities Act (S32). The first part of Kennedy's bill calls for the National Science Foundation to be given broader powers in formulating US science policy, and that, of course, is a central part of the reorganization plan announced last week. They also believe that the last part of the bill, calling for retraining programmes for unemployed scientists and engineers, will lose some political appeal if the projected improvement in the unemployment situation materializes. Discussion of the bill would then boil down to its provision for increasing the applied research and development activities of the National Science Foundation. But Congressional supporters of the legislation do not see it that way. For one thing, the bill's statement of objectives would require expenditures on civilian science to increase until they at least reach parity with expenditures on military science, and thereafter to grow at the same rate as the gross national product; the Administration's budget holds out little hope of such growth. 